NASA Technical Memorandum 102448

AIAA-90-0199

\title{
Convective Heat Transfer Measurements from a NACA 0012 Airfoil in Flight and in the NASA Lewis Icing Research Tunnel
}

Philip E. Poinsatte and G. James Van Fossen

Lewis Research Center

Cleveland, Ohio

and

Kenneth J. DeWitt

The University of Toledo

Toledo, Ohio

Prepared for the

28th Aerospace Sciences Meeting

sponsored by the American Institute of Aeronautics and Astronautics

Reno, Nevada, January 8-11, 1990 


\section{$+\cdots$}




\title{
CONVECTIVE HEAT TRANSFER MEASUREMENTS FROM A NACA 0012 AIRFOIL IN FLIGHT AND IN THE NASA LEWIS ICING RESEARCH TUNNEL
}

\author{
Philip E. Poinsatte and G. James Van Fossen \\ NASA Lewis Research Center \\ Cleveland, Ohio 44135 \\ Kenneth J. DeWitt \\ Dept. of Chemical Engineering \\ The University of Toledo \\ Toledo, Ohio 43606
}

\begin{abstract}
Local heat transfer coefficients were measured on a smooth and roughened NACA 0012 airfoil. Heat transfer measurements on the $0.533 \mathrm{~m}$ chord airfoil were made both in flight on the NASA Lewis Twin Otter Icing Research Aircraft and in the NASA Lewis Icing Research Tunnel (IRT). Roughness was obtained by the attachment of uniform $2 \mathrm{~mm}$ diameter hemispheres to the airfoil surface in four distinct patterns. Flight data were taken for the smooth and roughened airfoil at various Reynolds numbers based on chord in the range $1.24 \times 10^{6}$ to $2.50 \times 10^{6}$ and at various angles of attack up to $4^{\circ}$. During these flight tests, the free stream velocity turbulence intensity was found to be very low $(<0.1 \%)$. Wind tunnel data were acquired in the Reynolds number range $1.20 \times 10^{6}$ to $4.52 \times 10^{6}$ and at angles of attack from $-4^{\circ}$ to $+8^{\circ}$. The turbulence intensity in the IRT was 0.5 to $0.7 \%$ with the cloud-generating sprays off.

A direct comparison was made between the results obtained in flight and in the Icing Research Tunnel. The higher level of turbulence in the IRT versus flight had little effect on the heat transfer for the lower Reynolds numbers but caused a moderate increase in heat transfer at the higher Reynolds numbers. Turning on the cloud-generating spray nozzle atomizing air in the IRT did not alter the heat transfer. Roughness generally increased the heat transfer by locally disturbing the boundary layer flow. Finally, the present data were compared with leading edge cylinder and flat plate heat transfer values which are often used to estimate airfoil heat transfer in computer codes.
\end{abstract}

\section{Nomenclature}

A surface area of gage

c chord length

Fr Frössling number based on chord

h local heat transfer coefficient

$\mathrm{k}$ thermal conductivity of air

M Mach number

$\mathrm{Nu}$ Nusselt number based on chord

$Q_{\mathrm{EI}}$ electric power input to heater

$Q_{\text {end }}$ heat loss from unguarded end of heater

$\mathbf{Q}_{\text {gap }}$ heat loss through gap

$Q_{\text {rad }}$ heat loss due to radiation

$\mathrm{Re}$ Reynolds number based on chord

$T$ film temperature

$T$, measured static temperature

$T_{t}$ total temperature

$T_{g}$ measured gage temperature

$\mathrm{V}$ free stream velocity

Greek symbols

$\varepsilon \quad$ surface emissivity of polished aluminum

$\mu \quad$ viscosity of air

$\rho$ density of air

$\sigma \quad$ Stefan-Boltzman constant

\section{Introduction}

The problem of ice accretion on aircraft has historically drawn considerable attention. The hazards associated with ice formation on wings and engine inlets are well studied and quite apparent. Glaze or rime ice formations on an airfoil add weight, reduce lift, increase drag and may cause flight control problems [1-4]. A further danger 
arises when pieces of ice shed off a wing or engine inlet and cause damage to parts of the aircraft such as the fan and compressor blades, tail, rotors, etc. Ice formation on rotary aircraft has drawn much study because of the difficulty of preventing or removing it [5]. These problems have once again come into focus for civilian and military aircraft, especially in the application of low-flying missiles and helicopters in regions of cooler climate.

The two general methods used to alleviate the problems of ice accretion are anti-icing and de-icing. Anti-icing methods prevent ice from forming, most often by heating the affected area above the water freezing temperature. De-icing methods, on the other hand, remove ice after it begins to grow but before it causes much adverse effect. This is generally accomplished by melting or mechanically cracking the ice and allowing centrifugal or aerodynamic forces to shed it. In order to most efficiently apply either of these methods, it is first necessary to attain a good understanding of the icing phenomenon and to be able to predict whether or not ice will grow under specific environmental conditions and for specific locations. Further, ice growth prediction is especially vital in applications in which no ice protection equipment is used. Key to this prediction is the heat transfer.

If an aircraft passes through cool air containing supercooled liquid water droplets, an energy balance shows that if the convective and evaporative cooling, as well as the warming of the impinging supercooled droplets to the freezing temperature, can overcome the kinetic and viscous heating and thus remove the latent heat of fusion from the impinging droplets, ice will form on the surface $[6,7,8]$. The dominant heat loss terms in the thermal analysis are convective and evaporative cooling; hence the importance of the local convective heat transfer coefficient, $h$.

Icing facilities and ice accretion modeling codes must accurately simulate heat transfer in natural icing conditions. Heat transfer is dependent on the free stream turbulence level, and since wind tunnels typically have higher turbulence levels than are found in flight, there may be a problem in using wind tunnels to predict flight conditions. In this study turbulence intensity has been measured up to a free stream velocity of $94 \mathrm{~m} / \mathrm{sec}$ ( 210 miles per hour) to be equal to or less than $0.7 \%$ in the NASA Lewis Icing Research Tunnel (IRT). Turbulence intensity for flight conditions measured during this study have been found to be too low to make a meaningful measurement $(<0.1 \%)$ for smooth air. Previous measurements in rough air below a layer of cumulus clouds have given somewhat higher levels $(0.2-0.4 \%)$.

One objective of the present tests was to determine the differences in local heat transfer from a smooth and roughened airfoil between flight and tunnel conditions. A second objective of this work was to obtain much needed airfoil heat transfer data to better describe the thermal physics occurring during the icing process and, specifically, to provide accurate airfoil heat transfer data for use in ice growth prediction computer codes. One such code, NASA's LEWICE [9], currently incorporates an integral boundary layer subroutine to calculate heat transfer coefficients. Often heat transfer from an airfoil is estimated with cylinder-in-crossflow heat transfer data for the stagnation region and flat plate heat transfer coefficients for the rest of the airfoil surface. The present tests provide actual data for a NACA 0012 airfoil for a smooth surface as well as for quantifiable roughness patterns.

Limited data currently exist for heat transfer from an airfoil. A NACA study (1946-1951) $[10,11]$ compared in-flight heat transfer from an airfoil, in clear air and during icing conditions, with results from the IRT. For the flight data two separate airfoils, a NACA 0012 and a NACA 65,2-016, were tested at a 0 degree angle of attack, while only the $65,2-016$ was subsequently used in the IRT. In the "flat plate" region (i.e., the region away from the stagnation area), the data showed a substantial difference between flight and IRT heat transfer on the forward portion of the airfoil where the boundary layer was laminar. The IRT data was over $30 \%$ higher than the flight data. This difference has been attributed to the higher turbulence intensities present in the IRT. This conclusion is also supported by the fact that the flight and IRT data agreed fairly well on the downstream portion of the airfoil where the boundary layer was assumed fully turbulent.

Besides being restricted to a $0^{\circ}$ angle of attack, two other factors limit the usefulness of the previous data for computer code predictions. First, the data set is incomplete and somewhat inconsistent in the stagnation region, the area where ice growth initiates. Secondly, data were not taken for a rough surface, which can significantly alter boundary layer characteristics and thus the 
local heat transfer. Roughness, the result of early ice growth, may force a laminar boundary layer into transition in the ice formation zone. This behavior was observed in recent experiments performed on a cylinder in crossflow under different turbulence and roughness conditions [12].

A 1985 study at the University of Kentucky [13] included the determination of heat transfer coefficients from a smooth NACA 0012 airfoil in a subsonic wind tunnel, as well as from a five minute ice accretion shape. The smooth airfoil measurements were taken at various angles of attack $\left(-8^{\circ}\right.$ through $\left.+8^{\circ}\right)$ and for a chord-based Reynolds number range of $7.6 \times 10^{5}$ to $2.0 \times 10^{6}$. The $0^{\circ}$ angle of attack data generally agreed with the NACA study and the data showed a larger angle dependence on the suction side as compared to the pressure side. Again, however, more complete roughness data is lacking.

The present study focused on heat transfer measurements on a NACA 0012 airfoil. The NACA 0012 was chosen because it is a symmetric profile that is commonly used in helicopter main rotor and tail rotor applications where it may not be possible to control ice growth by electric heating or pneumatic boots. Local heat transfer coefficients were calculated from measurements taken on the forward 8 percent chord of a smooth and roughened NACA 0012 airfoil with a $0.533 \mathrm{~m}(21$ in) chord length. Roughness was obtained by the attachment of small hemispheres of uniform size ( $2 \mathrm{~mm}$ diameter) onto the airfoil in a set and reproducible pattern. Several distinct position patterns, similar to those employed by Schlicting [14] in his boundary layer work, were used. These patterns were chosen to facilitate numerical modeling of the roughness in various computer codes. Heat transfer measurements were recorded in flight on the NASA Lewis Twin Otter icing research aircraft and in the NASA Lewis Icing Research Tunnel. Flight data were collected for smooth and roughened surfaces at various aircraft speeds and various angles of attack up to $4^{\circ}$. Data were acquired in the IRT for smooth and roughened airfoil surfaces at various tunnel airspeeds, with and without spray nozzle atomizing air, and for various angles of attack from $-4^{\circ}$ (heat flux gages on the pressure side) to $+8^{\circ}$ (heat flux gages on the suction side). Detailed results of the flight tests, including comparisons with published data, have previously been reported in Reference 15. Selected data from the IRT and flight tests will be presented here as Frössling number versus position on the airfoil for various roughness patterns and angles of attack. Stagnation region data are compared with Frössling's cylinder-incrossflow solution [16] and data further aft on the airfoil are compared with flat plate correlations [17]. Complete results are available in Reference 18.

\section{Experiment Equipment and Procedure}

Apparatus

\section{NACA 0012 Test.Airfoil}

Heat transfer measurements were made on a NACA 0012 airfoil which was made of mahogany and had a chord length of $0.533 \mathrm{~m}$ (21 in) and a span length of $1.8 \mathrm{~m}(6 \mathrm{ft})$. The airfoil is shown in Figure 1.

An array of heat transfer gages was located in a removable section at the center of the span. Each heat flux gage was equipped with a thermocouple and foil heater which were connected to individual circuits that allowed the gages to be operated in a constant temperature mode. Figure 2 shows a cross-section of the airfoil and the location of the heat transfer gages. Table 1 lists the surface distance from the geometric stagnation point to the center of each gage and its heat transfer surface area. The airfoil actually contained twenty-eight heat flux gages but only twelve of them in the forward region were used in this study. A computerized data acquisition system was employed to record voltage and current input to each gage as well as gage temperature. Details of the model and instrumentation can be found in References 15 and 18.

Surface roughness was added to the airfoil by fastening hemispheres of silver alloy to the surface with cyanoacrylic adhesive. The hemispheres were $2 \mathrm{~mm}$ in diameter and were attached to the airfoil in different patterns. Three patterns were employed in the flight tests while four were used in the tunnel tests. Figure 3 shows planar sketches of the location of the roughness elements relative to the heat flux gages for each of the patterns. The thermal resistance of the gage surface was not altered significantly because of the sparse spacing of the elements and the high conductivity of the silver alloy. A numerical heat conduction computer model predicted that the temperature at the tip of each roughness element was less than $0.28^{\circ} \mathrm{C}$ 
$\left(0.5^{\circ} \mathrm{F}\right)$ lower than the temperature of the smooth aluminum gage surface. Also, each roughness element generally increased the heat transfer surface area by only one percent per gage. No attempt was made to account for the presence of the roughness elements in the data reduction.

\section{Twin Otter Aircraft.}

The NACA 0012 airfoil was flown atop the NASA Lewis Twin Otter Icing Research Aircraft. Details of the aircraft and parameter measurements are found in References 15 and 18. With the NACA 0012 research airfoil mounted vertically on the top of the aircraft the maximum sustainable speed was around $69 \mathrm{~m} / \mathrm{sec}(154 \mathrm{miles}$ per hour) at $1585-2250 \mathrm{~m}(5200-7400 \mathrm{ft})$ pressure altitude and a temperature range of $10-21^{\circ} \mathrm{C}(50$ $70^{\circ} \mathrm{F}$ ). Variance of the test airfoil angle of attack was achieved through yawing the aircraft with a combination of rudder and aileron. Flight tests were performed in darkness to avoid any effect that solar heating may have had on the heat flux gage temperatures.

\section{Icing Research Tunnel}

The NACA 0012 heat transfer airfoil was also tested in the NASA-Lewis Icing Research Tunnel (IRT). The IRT is a closed-loop subsonic refrigerated air tunnel used primarily for icing studies. A plan view of the IRT is shown in Figure 4. Air flow is induced by a 5000 horsepower, $7.31 \mathrm{~m}$ $(24 \mathrm{ft}$ ) diameter fan, and airspeed in the 1.83 by $2.74 \mathrm{~m}$ ( 6 by $9 \mathrm{ft}$ ) test section can be varied from about 9 to $125 \mathrm{~m} / \mathrm{sec}$ (20 to 280 miles per hour). The air is cooled by passage through a heat exchanger unit which maintained total air temperature around $-6.7^{\circ} \mathrm{C}\left(20^{\circ} \mathrm{F}\right)$, plus or minus $0.55^{\circ} \mathrm{C}\left(1^{\circ} \mathrm{F}\right)$. The tunnel air temperature was measured by an array of eleven thermocouples positioned on the first turning vane upstream of the test section. Spray bars, located approximately $14.6 \mathrm{~m} \mathrm{(48 \textrm {ft } )}$ upstream of the test section, are used to produce the icing cloud. The spray bars contain a collection of spray nozzles which shoot a combination of pressurized air and water to yield a continuous and uniform cloud of very small supercooled water droplets. The spray bars are also heated with a separate closed steam loop to prevent nozzle freezeup. The liquid water content of the tunnel icing cloud can generally range from about 0.2 to 3.0 $\mathrm{gr} / \mathrm{m}^{3}$, and the drop diameter can range from about 5 to $40 \mu \mathrm{m}$ [19]. Typical cloud conditions require the nozzle atomizing spray air to be set at $60 \mathrm{psi}$ and due to facility constraints roughly $82^{\circ} \mathrm{C}\left(180^{\circ} \mathrm{F}\right)$. In the present heat transfer tests, ice growth on the airfoil was to be avoided; therefore, when the spray bars were employed, only the 60 psi air was used. No water was passed through the nozzles.

Airspeed was measured using a Pitot-static probe attached to the wall in the tunnel test section. It was positioned roughly $3.05 \mathrm{~m}(10 \mathrm{ft})$ in front of the test airfoil, about $63 \mathrm{~cm}$ (25 in) from the ceiling and $51 \mathrm{~cm}$ (20 in) from the wall. The velocity determined at this point was assumed to be the free stream velocity at the center of the tunnel and based on many years experience with the tunnel this assumption is correct within $0.9-1.3 \mathrm{~m} / \mathrm{sec}(2-3$ miles per hour).

The airfoil was mounted vertically on the turntable in the floor of the test section as shown in Figure 5. The lower end was fastened to the floor turntable so that the chord of the airfoil was parallel to the tunnel walls when the turntable angle was set at zero degrees. The top of the airfoil was fitted with a metal collar and attached to the tunnel ceiling at a single point such that the airfoil could rotate with the turntable.

Test Procedure

\section{Turbulence Measurements}

Turbulence measurements were made with a standard constant temperature hot wire anemometer operating in an uncalibrated mode [20]. Turbulence measurements for the flight tests are described in References 15 and 18.

Turbulence measurements were made in the IRT with the same constant temperature hot wire equipment that was used in the flight tests. The probe, consisting of a single tungsten wire, was positioned in the center of the tunnel about a foot in front of the gages on the test airfoil. Turbulence intensities were measured with the cloud making nozzle atomizing air sprays off. Turbulence measurements with the cloud making air sprays turned on were found to be difficult to measure with hot wire equipment because the ambient tunnel air temperature generally averaged $6.7^{\circ} \mathrm{C}\left(20^{\circ} \mathrm{F}\right)$ while the spray air temperature had to be maintained near $82^{\circ} \mathrm{C}\left(180^{\circ} \mathrm{F}\right)$ due to facility limitations. Since hot wire equipment is a heat transfer sensing device, turbulence readings would be affected by 
this temperature difference and would not measure true turbulent velocity fluctuations.

\section{Heat Transfer Measurements}

\section{Elight Measurements}

All heat transfer data acquisition flights were made in darkness to avoid solar radiation on the gages and the airfoil. Flights were conducted at an altitude that provided smooth atmospheric conditions.

When steady-state air flow conditions were established, the heated aluminum strips were adjusted to a uniform temperature which was typically in the range of $32-41^{\circ} \mathrm{C}\left(90-105^{\circ} \mathrm{F}\right)$. When steady state thermal conditions were reached, data recording was initiated. About two minutes were required to obtain and record the required ten scans of all data channels.

\section{Icing Research Tunnel Measurements}

The heat transfer tests done in the IRT were performed in much the same way as the flight tests. After the initial tunnel cooldown, the heat transfer experiments were begun. The airfoil angle of attack was set by rotating the turntable to the desired position and the tunnel air velocity was varied by adjusting the fan speed. When steady state tunnel conditions were achieved, the airfoil heaters were adjusted to a uniform temperature, typically in the range of 32 to $38^{\circ} \mathrm{C}\left(90\right.$ to $\left.100^{\circ} \mathrm{F}\right)$. Again, data recording was initiated after steady state thermal conditions were obtained. Roughly two minutes were required to obtain and record ten scans of all data channels. Runs were made with and without the cloud generating spray air turned on.

\section{Data Reduction}

The average heat transfer coefficient from each gage was obtained from the applied voltage and current and the calculated temperature difference between the gage and the free stream total temperature. Since only the convective heat transfer was desired, the radiation heat loss had to be subtracted from the total electric power input to each heater. Further, the heater gages embedded in the airfoil were secured in place and separated from each other by an epoxy resin. Some heat was conducted from the edges of each heater gage through the epoxy and convected from the surface of the airfoil in the gaps between the gages and from the unguarded ends of the gages. These losses were also subtracted from the electric power. Therefore, the local heat transfer coefficient, $h$, for each aluminum heater gage was calculated from:

$$
\mathrm{h}=\left(\mathrm{Q}_{\mathrm{E} 1}-\mathrm{Q}_{\mathrm{rad}}-\mathrm{Q}_{\mathrm{gap}}-\mathrm{Q}_{\mathrm{end}}\right) /\left(\mathrm{A}\left(\mathrm{T}_{\mathrm{g}}-\mathrm{T}_{\mathrm{t}}\right)\right)
$$

where $Q_{E I}$ (voltage x current) is the total electric power input to each heater. The quantity $Q_{\text {rad }}$ is the radiation heat loss, which is estimated by:

$$
Q_{\text {rad }}=\sigma A \varepsilon\left(T_{t}^{4}-T_{t}{ }^{4}\right)
$$

A value of 0.045 was used for $\varepsilon$, the emissivity of polished aluminum, and $\sigma$ is the Stefan-Boltzman constant. The quantities $\mathbf{Q}_{\text {gap }}$ and $\mathbf{Q}_{\text {end }}$ are the heat lost through the epoxy gaps separating the aluminum gages and the unguarded ends of the heaters, respectively. These quantities were obtained from an exact solution for heat conduction in a rectangle with appropriate boundary conditions, which is detailed in Reference 18 . The remaining quantities are: $A$, the surface area of each aluminum strip; $T_{g}$, the measured wall temperature of each gage; and $T_{t}$, the total temperature. For the flight data, $T_{\mathfrak{t}}$ was calculated from the measured static temperature, $T_{2}$, and the true airspeed, i.e.,

$$
\mathrm{T}_{\mathrm{t}}=\mathrm{T}_{\mathrm{t}}(1+\mathrm{M} / 5)
$$

where $M$ is the Mach number. Typical values for $T_{t}$ ranged from 10 to $21^{\circ} \mathrm{C}\left(50\right.$ to $\left.70^{\circ} \mathrm{F}\right)$. For the IRT data, $T_{t}$ was measured with two thermocouples positioned on the leading edge of the airfoil and was typically around $-6.7^{\circ} \mathrm{C}\left(20^{\circ} \mathrm{F}\right)$.

The heat transfer data in this analysis is presented as Frössling number based on chord length which is calculated as:

$$
\mathrm{Fr}=\mathrm{Nu} / \mathrm{Re}^{0.5}=\left[(\mathrm{hc} / \mathrm{k}) /(\rho \mathrm{Vc} / \mu)^{0.5}\right]
$$

where $c$ is the $0.533 \mathrm{~m}(21 \mathrm{in})$ chord length. The density, $\rho$, was calculated from the ideal gas relation for air using the static temperature and pressure at the test airfoil location. The velocity, V, for flight data was measured with Twin Otter instrumentation and converted to the true test section velocity with the aid of calibrations obtained on previous Twin Otter flights, while the velocity for the tunnel data was measured with the IRT Pitot static probe. The thermal conductivity, $k$, and viscosity, $\mu$, were obtained as functions of temperature from air data in Reference 21. These thermal properties were evaluated at the film temperature given by:

$$
T_{t}=\left(T_{t}+T_{t}\right) / 2
$$


An uncertainty analysis according to the method of Kline and McClintock [22] was performed on the calculated local heat transfer coefficient and the Frössling number. The uncertainties for each gage were similar and averaged around $4.5 \%$ for $h$ and $5 \%$ for Fr. A substantial part of this uncertainty was found to be due to uncertainty in the gap heat loss term because the thermal conductivity of the epoxy gap material was not known exactly and was assumed to be 0.11 (with a $\pm 50 \%$ uncertainty), a typical value for epoxy of this nature. This would not be a random error but would tend to bias the data either high or low. However, good general agreement with flat plate data seemed to confirm that the epoxy thermal conductivity value used was correct.

\section{Results and Discussion}

In this section selected results of the heat transfer tests conducted in the Icing Research Tunnel (IRT) as well as data obtained during the Twin Otter aircraft flights will be presented. Special emphasis is given to the effect on heat transfer of the different free stream turbulence levels. The turbulence intensity measured with hot wire equipment during the flight runs was found to be very low $(<0.1 \%)$. However, in the IRT with the cloud making sprays off, the turbulence intensity level was found to be $0.6,0.52$ and $0.7 \%$ at tunnel air speeds of 31,63 , and $94 \mathrm{~m} / \mathrm{sec}(70,140$ and 210 miles per hour), respectively. Previous studies measured the IRT turbulence levels to be around $0.5 \%$ with the cloud making air sprays off and around $2 \%$ with spray equipment operating; howev$\mathrm{er}$, this latter result is somewhat suspect because of the aforementioned concerns regarding the required spray air temperature.

Generally the IRT data exhibited the same trends as the flight data previously reported in Reference 15. Figure 6 shows Frössling number based on chord as a function of $\mathrm{s} / \mathrm{c}$ for the smooth airfoil at a $0^{\circ}$ angle of attack without and with tunnel spray air for several Reynolds numbers. The data plotted in this manner collapse onto a single curve which shows that the Nusselt number is proportional to the square root of the Reynolds number. A least squares curve fit of the equation

$$
\mathrm{Nu}=\mathrm{A}(\mathrm{Re})^{\mathrm{B}}
$$

for the tunnel data [18] showed that the Nusselt number did correlate with Reynolds number raised to the 0.5 power. It should be noted here that the flight Nusselt number data more accurately correlated with Reynolds number raised to the power of around 0.43 . However a sufficiently good correlation with the square root of the Reynolds number was found to justify presentation of the data as Frössling number. The solid line on the figure represents the averaged, smooth-surface, $0^{\circ}$ angle of attack, flight data and will be reproduced on subsequent figures for reference. As expected, the Frössling number is greatest at the stagnation point, with an average value of 4.56 , and then trails off smoothly to an average value of 1.06 at an $\mathrm{s} / \mathrm{c}$ value of 0.083 . The IRT stagnation point average value of 4.56 is only $6 \%$ higher than the average stagnation value of 4.30 for the flight data. The correlations developed by Lowery and Vachon [23] predict a stagnation point heat transfer enhancement due to a $0.7 \%$ free stream turbulence of $3.5 \%$ at Reynolds number of $1.2 \times 10^{6}$ and $5.9 \%$ at Reynolds number of $3.5 \times 10^{6}$. The reason for the "bump" at $\mathrm{s} / \mathrm{c}$ $=0.048$ is unknown; there are no obvious rough spots or steps on the surface of the airfoil at this or any other point. This same bump was present in the flight data.

It is possible to define the Frössling number in terms of the diameter of a cylinder inscribed in the leading edge of the airfoil. This allows comparison of Frössling's analytical solution for heat transfer in the stagnation region of a circular cylinder [16] with the present data. For a NACA 0012 airfoil, the leading edge equivalent diameter is $3.16 \%$ of the chord or $0.0169 \mathrm{~m}(0.664 \mathrm{in})$ for the airfoil tested [24]. The experimental average Frössling number based on leading edge equivalent diameter for the smooth airfoil was found to be 0.806 , roughly $15 \%$ lower than the 0.945 value predicted by Frössling's cylinder solution. Frössling's analytical results are often used with an equivalent leading edge diameter to compute heat transfer in the stagnation region for airfoils and turbine blades. However, it is uncertain as to whether the validity of this method has been proven experimentally.

For comparison purposes, representative cases of smooth and roughened tunnel and flight data under similar conditions (i.e. same angle of attack and comparable Reynolds numbers) will be presented.

Figure 7 shows the heat transfer results for both spray conditions of the IRT tests as well as for the flight test. This data is for the smooth airfoil at 
a $0^{\circ}$ angle of attack and a nominal Reynolds number equal to $1.2 \times 10^{6}$. Compared with the flight data, gages 2-6 show a Frössling number only 2-3\% higher for the tunnel cases without spray air, and 3$5 \%$ higher with spray air. Further aft on the airfoil ( $\mathrm{s} / \mathrm{c}>0.03$ ), the Frössling number averages $6 \%$ higher both with and without spray air cases. All of these values are within the limits of the calculated experimental uncertainty.

Figure 8 shows similar Frössling number behavior for a nominal Reynolds number of $2.4 \times 10^{6}$. The two tunnel cases, with and without spray air, again agree quite well (within 2\%). However, comparing both cases with the flight data shows that the Frössling number tunnel data is roughly $7 \%$ higher on gages $2-6$ and $10 \%$ higher on gages greater than 6.

The $2^{\circ}$ and $4^{\circ}$ angle of attack smooth-airfoil data exhibited similar behavior, showing good general agreement between tunnel and flight data at the lower Reynolds numbers, while at the higher Reynolds numbers the Frössling numbers for the tunnel cases were somewhat higher than the flight data.

It seems evident that the small increase in turbulence level has a slight affect on the heat transfer and this effect is magnified with increasing Reynolds number. A consequence of this behavior is seen in the Nusselt versus Reynolds number power law constants. Generally the exponents on the downstream gages of the IRT data are slightly higher than the corresponding flight data. Further, and perhaps more importantly, the addition of spray air (recall that in these experiments only spray air and not any spray water was turned on) to the tunnel stream does not affect the heat transfer and thus apparently does not affect the turbulence level. It should be mentioned, however, that it is possible that the spray air does increase the tunnel turbulence but the leading edge heat transfer is not sensitive to this change.

The addition of surface roughness to the leading edge of the airfoil as shown in Figure 3a, for $0^{\circ}$ angle of attack, locally increased the stagnation point heat transfer about $10 \%$ but did not appear to affect the downstream heat transfer. This increase can be partially explained by the $4 \%$ increase in surface area due to the presence of the hemispherical roughness elements. It could also be attributed to a disturbance of the boundary layer by the relatively huge roughness elements followed by a return to laminar flow sufficiently past the leading edge trip point.

The sparsely roughened airfoil (Figure $3 b$ ) exhibited similar behavior. The flight and tunnel data for the sparsely roughened airfoil at a $0^{\circ}$ angle of attack and Reynolds numbers $1.2 \times 10^{6}$ and $2.4 \times 10^{6}$ are presented in Figures 9 and 10, respectively. The axial positions of the roughness elements are denoted by the arrows above the abscissa. Compared with the smooth-airfoil cases the data show an increase in heat transfer on the stagnation gage which is similar to the leading edge roughness case. Downstream of the stagnation region, the Frössling number exhibits a pattern of increasing at and immediately downstream of the roughness row position, then falls off slightly. Note that the downstream gages show somewhat higher Frössling numbers for the higher Reynolds number (Figure 10) versus the lower Reynolds number case (Figure 11). The power law curve fits showed that at an $s / c$ greater than 0.02 , the Nusselt number begins moving to a Reynolds number dependence higher than $\mathrm{Re}^{0.5}$. This trend was especially true for the tunnel data and it is an indication of boundary layer transition. With few exceptions the flight and tunnel Frössling number values on most gages agreed within the uncertainty limits for the low Reynolds number case. At the higher Reynolds number, as with the smooth case, the two tunnel conditions agreed quite well, but most gages for both cases show Frössling number values 4-10\% higher than corresponding flight values. Similar trends were also observed on the $2^{\circ}$ and $4^{\circ}$ angle of attack data, though the $4^{\circ}$ case exhibited somewhat higher magnitude; some gages for the $2.4 \times 10^{6}$ Reynolds number show tunnel heat transfer data up to $16 \%$ higher than the flight data.

Increasing the density of the roughness elements from the sparse to the dense 1 pattern (Figure 3c) has a dramatic effect on the heat transfer downstream. The data for the $0^{\circ}$ angle of attack, dense 1 roughened airfoil are illustrated in Figures 11 and 12. The heat transfer from gages 28 is substantially higher than the corresponding sparsely roughened case. Further downstream past gage 7 , the density of roughness elements decreases, and at gages 10 and 11 , the effect of the increased density of the roughness elements upstream seems to have nearly damped out. This trend indicates that if there is roughness of sufficient magnitude present, the boundary layer is 
perturbed locally and immediately downstream. However, as the density of roughness is reduced in the downstream direction, the heat transfer recovers to a level that is consistent with the sparse roughness pattern.

For the lower Reynolds number of $1.2 \times 10^{6}$, both tunnel data sets again agree; however, they show values $2-8 \%$ higher than the flight data. The $2.4 \times 10^{6}$ Reynolds number case illustrates similar behavior, with the tunnel data being $18-25 \%$ higher than the flight data. This result is somewhat surprising because it would seem that as the boundary layer is more and more disturbed by the roughness, the free stream turbulence would have less and less effect on the Frössling number. However, in this dense 1 case the free stream turbulence appears to have a greater effect on the heat transfer than in the sparse roughness cases. Moving to a higher angle of attack did not alter this trend.

Frössling data versus $s / c$ for the $0^{\circ}$, dense 2 roughness pattern (Figure $3 \mathrm{~d}$ ) are presented for low and high Reynolds number cases in Figures 13 and 14 , respectively. Note that these graphs show only tunnel data, as no dense 2 flight data were acquired. Examination of Figure 3 shows that the dense 2 roughness pattern is very similar to the dense 1 roughness pattern, except that the roughness element density is constant throughout and does not decrease at $\mathrm{s} / \mathrm{c}$ greater than 0.04 as the dense 1 pattern does. As expected, the heat transfer results shown in these dense 2 graphs are very similar to the results of the dense 1 cases. The only notable difference between the dense 2 and the dense 1 cases occurs in the region for $s / c$ greater than 0.04 . The Frössling number in the dense 2 cases in this region, while still falling off from the gage 7 maximum and then leveling off, is somewhat higher than the dense 1 data. Thus, the dense 2 roughness data exhibit the same heat transfer behavior as the dense 1 cases, except that the dense 2 data yield a higher Frössling number in the region of higher roughness density $(\mathrm{s} / \mathrm{c}>0.04)$. There is no upstream heat transfer effect due to the increase of downstream roughness density.

Generally, it would seem that the IRT is a relatively clean wind tunnel, at least with respect to heat transfer in the forward portion of an airfoil. The slightly higher turbulence level in the tunnel had minimal effect on the heat transfer from the smooth airfoil at the lower Reynolds number; the higher Reynolds number did illustrate a greater turbulence induced heat transfer increase. The addition of surface roughness, however, seemed to magnify the effect of turbulence on heat transfer. The addition of spray atomizing air had virtually no effect on the heat transfer, and it is therefore believed that the spray air did not significantly alter the free stream turbulence level in the tunnel.

The general Frössling number dependence on angle of attack is illustrated in Figure 15 for the smooth airfoil and Figure 16 for the sparsely roughened airfoil. Figure 15 shows IRT with spray air Frössling number data for the smooth airfoil at a $1.2 \times 10^{6}$ nominal Reynolds number, for $0^{\circ}, 2^{\circ}, 4^{\circ}$ and $6^{\circ}$ angle of attack. Data for the suction side of the airfoil are represented by positive s/c values. The stagnation gage heat transfer generally increases with angle of attack while the first pressure gage decreases going from $0^{\circ}$ to $2^{\circ}$ to $4^{\circ}$, then increases from $4^{\circ}$ to $6^{\circ}$. This behavior can be explained by the movement of the aerodynamic stagnation point; the stagnation region sees an effectively larger leading edge radius as it moves toward gage 3 with $2^{\circ}$ and $4^{\circ}$ angle of attack, and this results in a lower heat transfer coefficient. The flow is then accelerated around the leading edge, thus increasing the heat transfer at the geometric stagnation point. Similarly, going to $6^{\circ}$ moves the aerodynamic stagnation point toward gage 2, causing an increase in gage 3 heat transfer. It should also be noted that the power law curve fits showed that as the aerodynamic stagnation point moves closer to the pressure side gages (gages 2 and 3 ), the $R e^{0.5}$ dependence is seen to exist at those gages, i.e., the Nusselt number at the aerodynamic stagnation point always has a $R^{0.5}$ dependence. On the suction side the heat transfer generally decreases with angle. However at $6^{\circ}$, the data illustrate a drastic rise in heat transfer at $\mathrm{s} / \mathrm{c}$ greater than 0.06 , which is most likely due to boundary layer transition.

The sparsely roughened airfoil data, meanwhile, exhibited similar behavior concerning the aerodynamic stagnation point, as evidenced by Figure 16. The downstream gages, however, showed the heat transfer increasing with increasing angle-of-attack. The other roughness cases exhibited similar angle of attack behavior.

Data were also acquired at a $-4^{\circ}$ angle of attack which allowed more complete measurement of pressure side heat transfer values. Comparing the $-4^{\circ}$ (pressure side) data with the $+4^{\circ}$ (suction side) 
data showed that for the smooth airfoil the pressure side heat transfer was slightly higher than the suction side, while for the roughened airfoil the pressure side experienced lower heat transfer than the suction side.

\section{Experimental Data Yersus Cylinder and Elat Plate Correlations}

In computer codes, heat transfer from airfoils is often estimated by using cylinder-in-cross-flow heat transfer values in the leading edge region and flat-plate heat transfer values further aft. Figures 17 and 18 show chord-based Frössling number values corresponding to Frössling's analytical cylinder-in-crossflow solution [16], together with laminar and turbulent flat-plate values [17] on the same graphs as the present $0^{\circ}$, smooth-airfoil flight and tunnel data (without spray air), respectively. Both graphs show good agreement with the laminar flat plate correlation at $\mathrm{s} / \mathrm{c}$ greater than 0.06 , the flight data averaging around $8 \%$ lower and the tunnel data around $3 \%$ higher. However, in the stagnation region the experimental heat transfer is somewhat lower than that predicted by Frössling. Gages 2-5 show a $19-21 \%$ lower Frössling number for the flight data and $14-17 \%$ lower for the tunnel data. In addition, both the flight and the IRT data fall between the laminar and turbulent flat-plate values for $0.01<\mathrm{s} / \mathrm{c}<0.06$. It seems, therefore, that the inscribed cylinder method for estimating the heat transfer from the forward portion of a NACA 0012 airfoil does not accurately work; in this case the method substantially overpredicts the measured heat transfer.

Figure 19 shows the IRT data for the dense 2, $0^{\circ}$, without-spray condition compared with the cylinder and flat plate heat transfer values. The heat transfer in the stagnation region for the dense 2 roughened airfoil agrees fairly well with Frössling's smooth-cylinder laminar flow solution. Moving downstream on the airfoil, the heat transfer drastically increases, reaching a maximum level near $s / c$ of 0.035 , and then decreases to a level fairly consistent with turbulent flow flat-plate heat transfer values. The measured heat transfer at specific Reynolds numbers are somewhat higher than their respective flat-plate turbulent values. However the higher measured heat transfer may be due to the increase in surface area due to the roughness elements (3-7\% increase on each gage for the dense roughness patterns) that was not taken into account in the data analysis. It may be mentioned here that the maximum heat transfer is in the same general region, if slightly aft, of ice horn growth observed during glaze ice accretion [2].

\section{Conclusions}

Local heat transfer measurements from a smooth and roughened NACA 0012 airfoil were successfully obtained in flight and in the NASA Lewis Icing Research Tunnel using the method and apparatus described in this work. are:

Major conclusions resulting from this study

1. The smooth-airfoil Frössling number data for flight with a measured turbulence intensity of $<0.1 \%$ and for the IRT with a $0.5-0.7 \%$ turbulence intensity showed fairly good agreement at the lower Reynolds number $\left(\operatorname{Re}=1.2 \times 10^{6}\right)$. At the higher Reynolds number $\left(\operatorname{Re}=2.4 \times 10^{6}\right)$, the IRT data were somewhat higher than the flight data. Comparison of the flight and tunnel rough-surface data showed that the effect of turbulence was a slight increase in heat transfer.

2. The IRT is a fairly clean wind tunnel, with a measured turbulence intensity around $0.5-0.7 \%$. The addition of spray air to the tunnel flow did not change the heat transfer, indicating that the turbulence level was not significantly altered by the spray air.

3. The addition of roughness to the airfoil surface drastically increased the heat transfer downstream of stagnation. The roughness elements disturbed the laminar boundary layer flow and in some cases caused a transition to turbulent flow.

4. Generally, the suction-side heat transfer on the smooth airfoil slowly decreased with angle of attack, however, at $6^{\circ}$ the downstream heat transfer drastically increased indicating that some flow transition had occurred. The roughened-airfoil cases showed the suction side heat transfer monotonically increasing with angle of attack. The Nusselt number for the smooth-and roughened-airfoil cases at the aerodynamic stagnation point always correlated with $R^{0.5}$.

5. The flight and tunnel smooth-airfoil data show good agreement with the laminar flat-plate heat transfer values for $\mathrm{s} / \mathrm{c}$ equal or greater than 0.06 . In the leading edge region, the measured heat transfer is somewhat lower than that predicted by 
Frössling's laminar flow cylinder solution: $15 \%$ lower in the IRT and $20 \%$ lower in flight. Therefore, it would appear that the method of using an inscribed cylinder for approximating the leading edge heat transfer does not work for the NACA 0012 airfoil.

\section{References}

1. Cebeci, T., "Effects of Environmentally Imposed Roughness on Airfoil Performance", NASA CR179639, June, 1987.

2. Olsen, W. A., Shaw, R. J. and J. E. Newton, "Ice Shapes and the Resulting Drag Increase for a NACA-0012 Airfoil", NASA TN-83556, January, 1984.

3. Bragg, M. B., Gregorek, G. M. and R. J. Shaw, "Wind Tunnel Investigation of Airfoil Performance Degradation Due to Icing", AIAA-82-0582, 1982.

4. Young, A. D.and J. H. Paterson, "Aircraft Excrescence Drag", AGARDograph No. 264, July, 1981.

5. Korkan, K D., "Performance Degradation of Propeller/Rotor Systems Due to Rime Ice Accretion", report delivered at NASA Lewis Research Center Icing Analysis Workshop, February, 1983.

6. Hardy, J. K., "Protection of Aircraft Against Ice", Royal Aeronautical Society Journal 51, 435, 1947.

7. Messinger, B. L., "Equilibrium Temperature of Unheated Icing Surface as a Function of Airspeed", Journal of Aeronautical Sciences 20, 29, 1953.

8. Cansdale, J. T. and I. I. McNaughtan, "Calculation of Surface Temperature and Ice Accretion Rate in a Mixed Water/Ice Crystal Cloud", RAE Technical Report 77090, June, 1977.

9. Ruff, G. A., "Users Manual for the NASA Lewis Ice Accretion Prediction Code (LEWICE)", to be published as a NASA-CR.

10. Neel, C. B., Bergrun, N. R., Jukoff, D. and B. A. Schlaff, "The Calculation of Heat Required for Wind Thermal Ice Prevention in Specified Icing Conditions", NACA TN-1472, 1947.

11. Gelder, T. F. and J. P. Lewis, "Comparison of
Heat Transfer from Airfoil in Natural and Simulated Icing Conditions", NACA-2480, September, 1951.

12. Van Fossen, G. J., Simoneau, R. J., Olsen, W. A. and R. J. Shaw, "Heat Transfer Distributions Around Nominal Ice Accretion Shapes Formed on a Cylinder in the NASA Lewis Icing Research Tunnel", AIAA paper 84-0017 presented at the AIAA 22nd Aerospace Sciences Meeting, Reno, Nevada, January, 1984. NASA TM-83557.

13. Pais, M. R.,Singh, S. N. and L. Zou, "Determination of the Local Heat Transfer Characteristics on Glaze Ice Accretions on a NACA0012 Airfoil", AIAA paper 88-0292, presented at AIAA 26th Aerospace Sciences Meeting, Reno, Nevada, January, 1988.

14. Schlicting, H., "Experimental Investigation of the Problem of Surface Roughness", NACA TM-823, April, 1937.

15. Newton, J. E., Van Fossen, G. J., Poinsatte, P. E. and K. J. DeWitt, "Measurement of Local Convective Heat Transfer Coefficients from a Smooth and Roughened NACA-0012 Airfoil: Flight Test Data", AIAA paper 88-0287 presented at AIAA 26th Aerospace Science Meeting, Reno, Nevada, January, 1988. NASA TM-100284.

16. Frossling, N., "Evaporation, Heat Transfer, and Velocity in Two Dimensional and Rotationally Symmetrical Laminar Boundary Layer Flow", NACA TM-1432, 1958.

17. Welty, J. R., Wicks, C. E., and R. E. Wilson, Eundamentals of Momentum, Heat, and Mass Transfer. Wiley \& Sons, 370, 1984.

18. Poinsatte, P. E., "Heat Transfer Measurements from a NACA 0012 Airfoil in Flight and in the NASA Lewis Icing Research Tunnel", MS Thesis, The University of Toledo, June, 1989. To be published as a NASA-CR.

19. Anon., "Icing Research Tunnel", brochure from ASME International Historic Landmark ceremony, NASA B-87-0011, May 20, 1987.

20. Anon., "Hot Wire and Hot Film Measurements and Applications", Thermal Systems, Inc., Technical Bulletin No. 4, 35. 
21. Hillsenrath, J., Beckett, C. W., Benedict, W. S., Fano, L. and H. J. Hobe, "Tables of Thermal Properties of Gases", NBS Circular 564, November, 1955.

22. Kline, S. J. and F. A. McClintock, "Describing Uncertainties in Single Sample Experiments", Mechanical Engineering, 75, 3, January, 1953.

23. Lowery, G. W., and Vachon, R. I., "The Effect of Turbulence on Heat Transfer from Unheated Cylinders", International Journal of Heat and Mass Transfer, 18, No. 11, 1229, November, 1975.

24. Abbott, I. H., von Doenhoff, A. E. and L. S. Stivers, "Summary of Airfoil Data, NACA Report No. 824, 71, 1945. 


\section{ORIGINAL PAGE \\ BLACK AND WHITE PHOTOGRAPH}

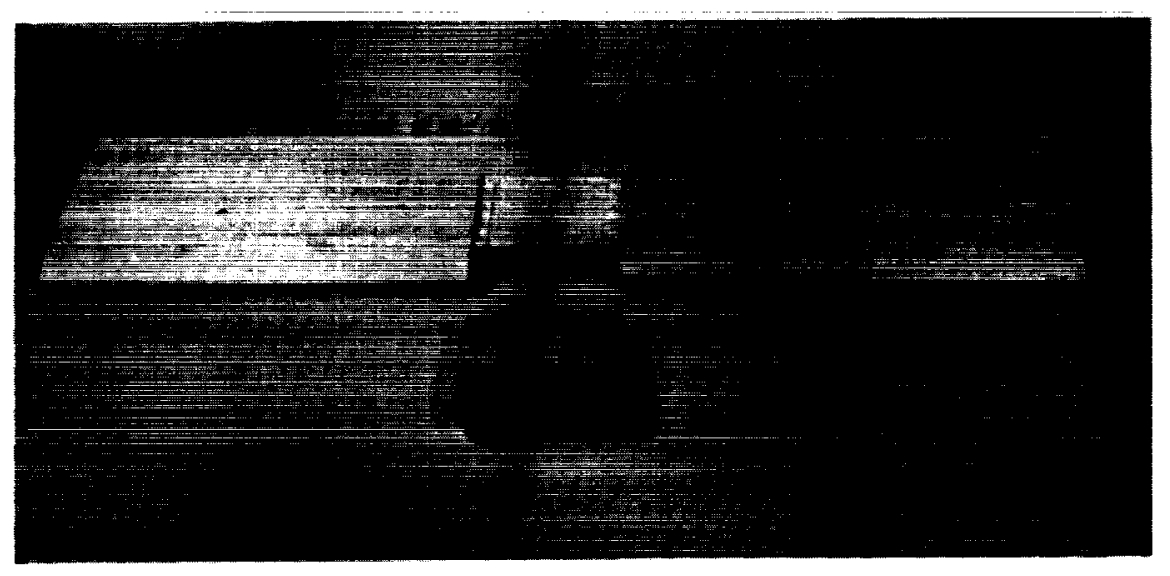

Figure 1. NACA 0012 test airfoil.

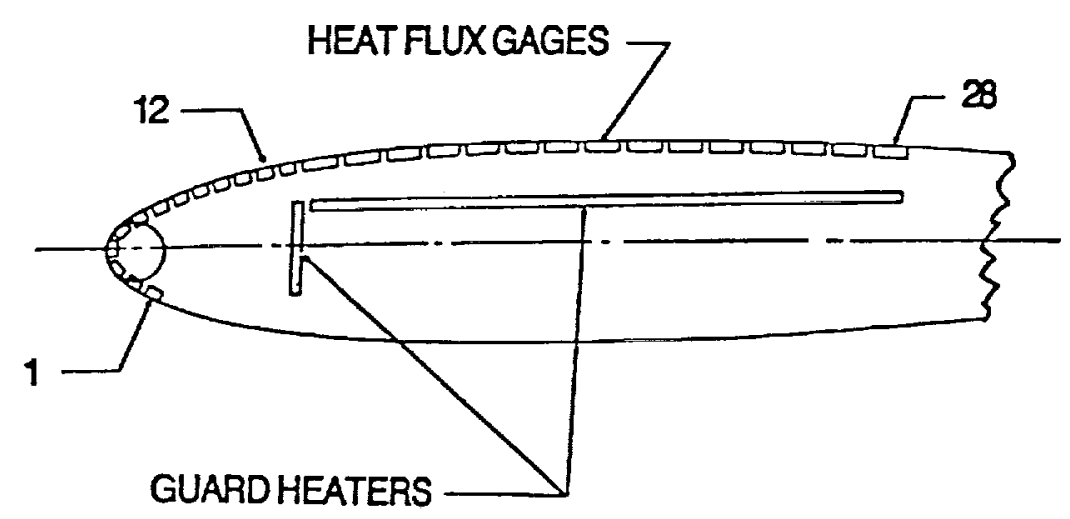

Figure 2. Cross-section of NACA 0012 airfoil with heat flux gages.

Table 1. Location and surface area of heat transfer gages.

\begin{tabular}{|c|c|c|}
\hline GAGE * & - S/C & $\begin{array}{c}\text { SURFACE } \\
\text { AREA } \\
\text { Sq.Cm. }\end{array}$ \\
\hline 1 & -0.036 & 3.145 \\
2 & -0.024 & 3.145 \\
3 & -0.012 & 3.145 \\
4 & 0 & 3.187 \\
5 & 0.012 & 3.145 \\
6 & 0.024 & 3.145 \\
7 & 0.036 & 3.145 \\
8 & 0.048 & 3.145 \\
9 & 0.060 & 3.145 \\
10 & 0.072 & 3.145 \\
11 & 0.083 & 3.145 \\
12 & 0.095 & 3.145 \\
\hline
\end{tabular}


(a)

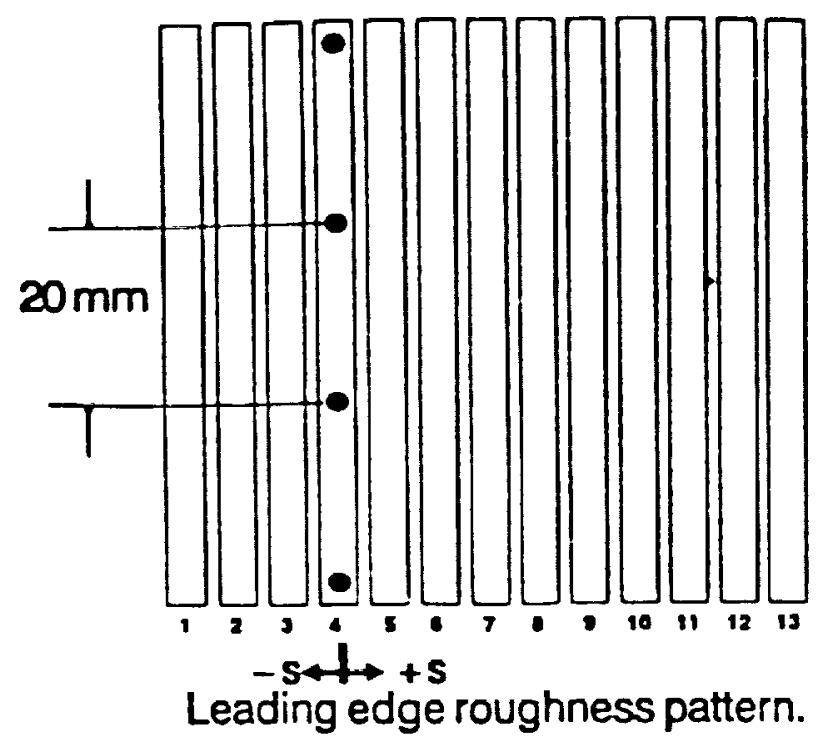

(c)

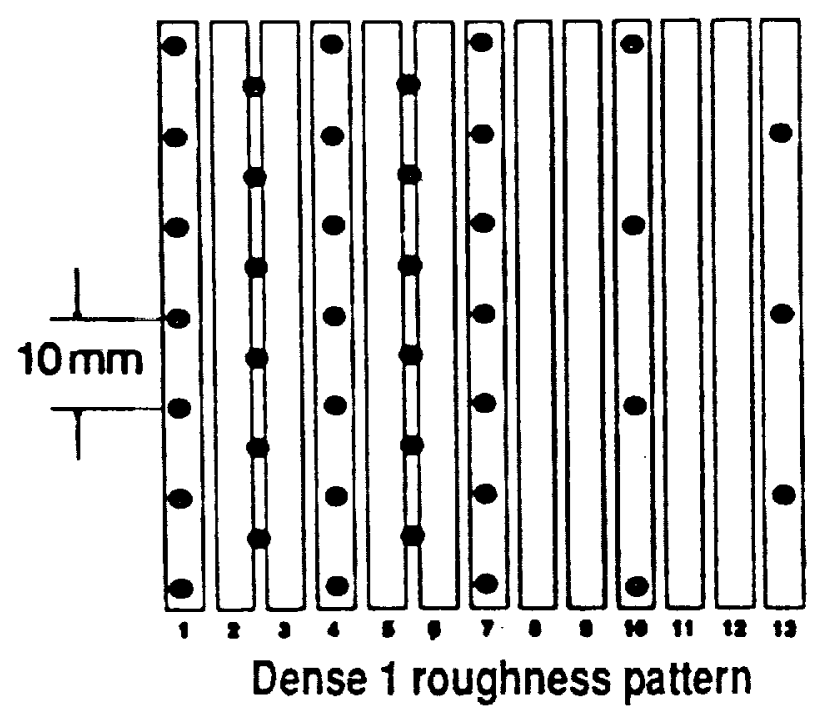

(b)

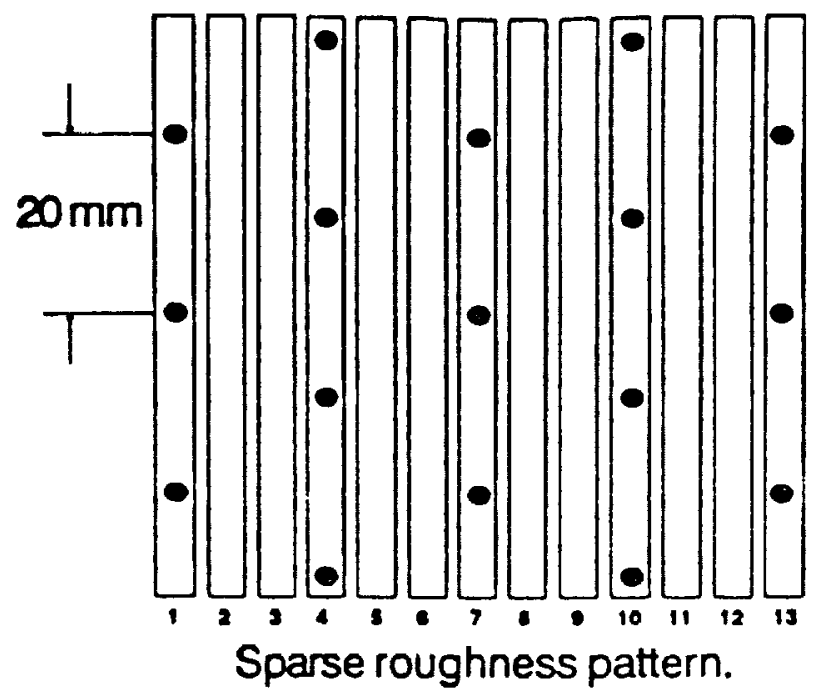

(d)

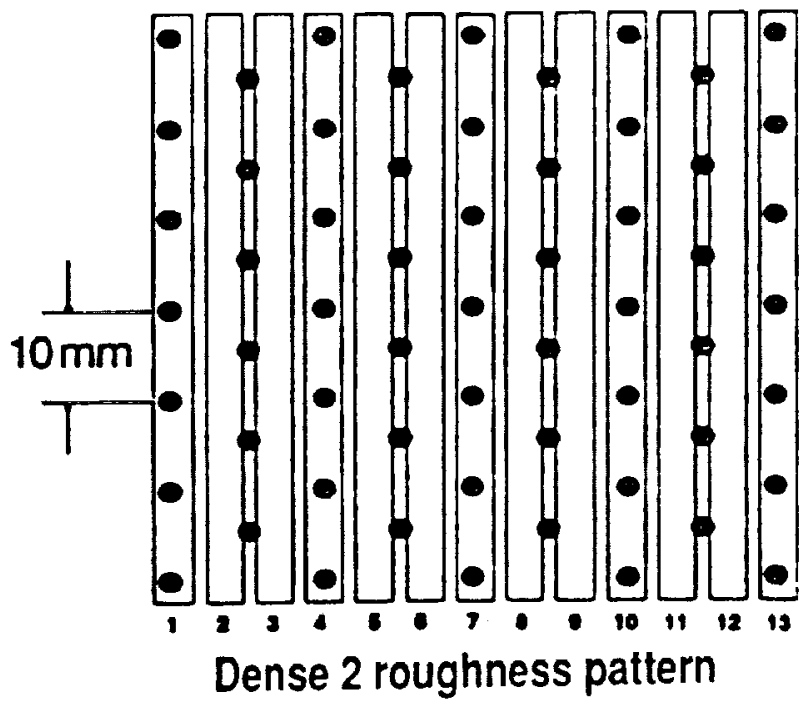

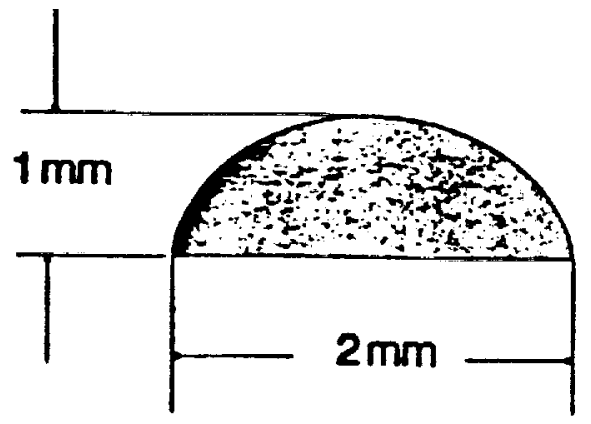

Typical roughness element.

Figure 3. Location of roughness elements relative to heat flux gages. 


\section{ORIGINAL PAGE \\ BLACK AND WHITE PHOTOGRAPH}

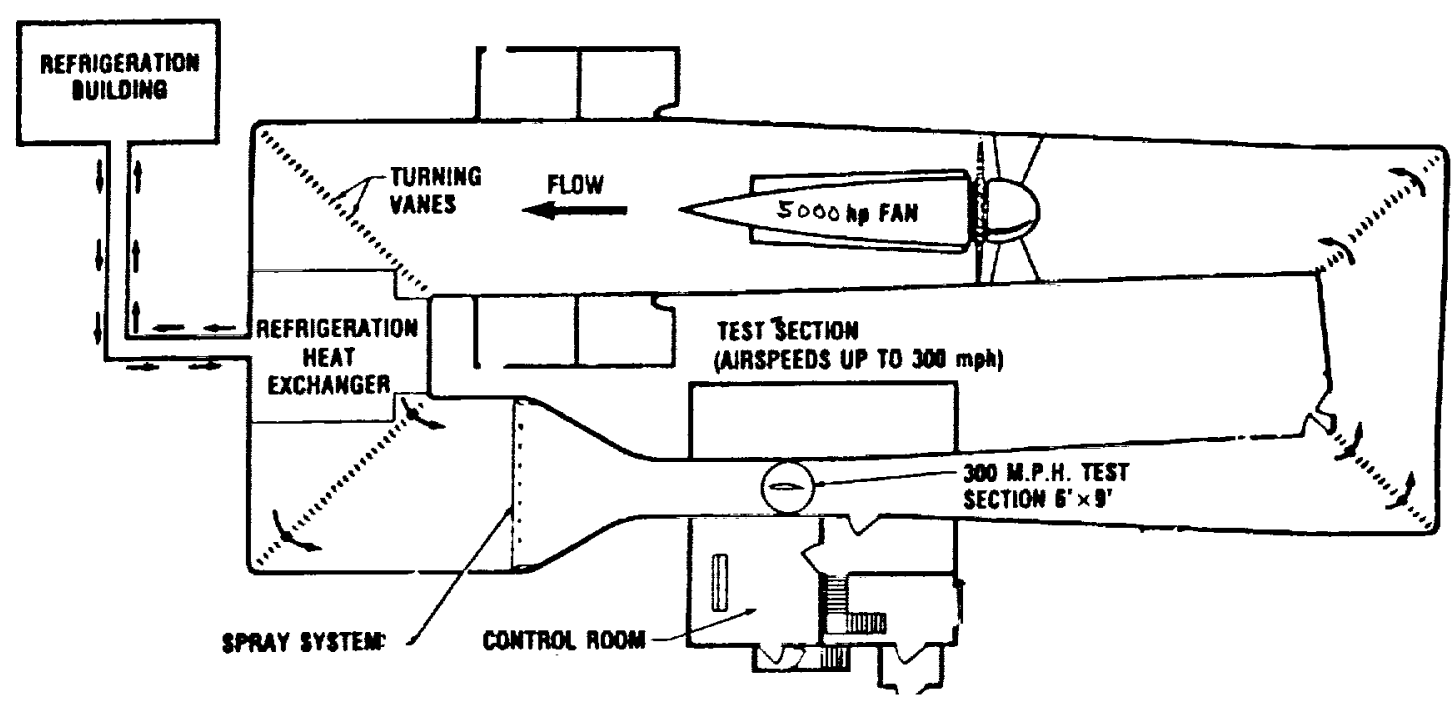

Figure 4. NASA Lewis Icing Research Tunnel.

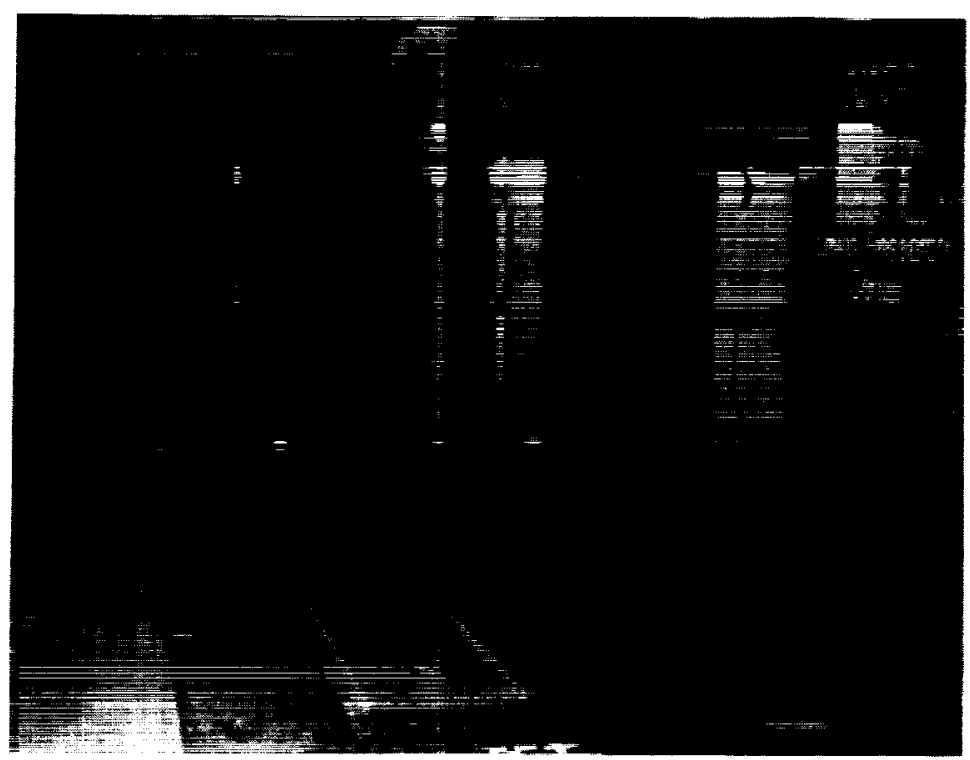

Figure 5. Test airfoil positioned in the Icing Research Tunnel. 


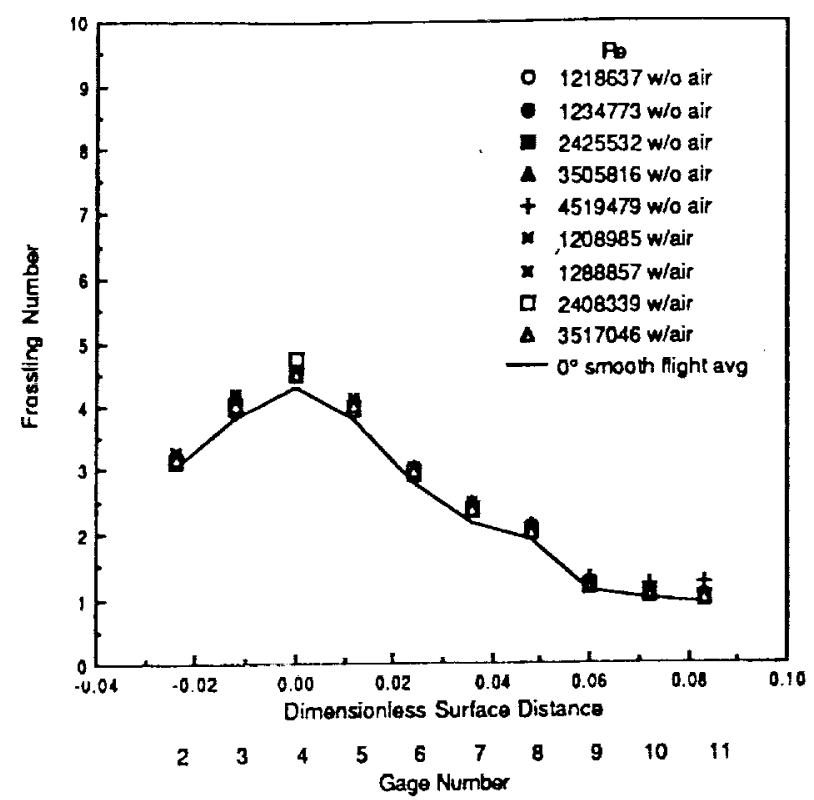

Figure 6. Frossling Number versus dimensionless surface distance: smooth alrfoil, $0^{\circ}$ angle of attack, without and with spray nozzel atomizing air, IRT data.

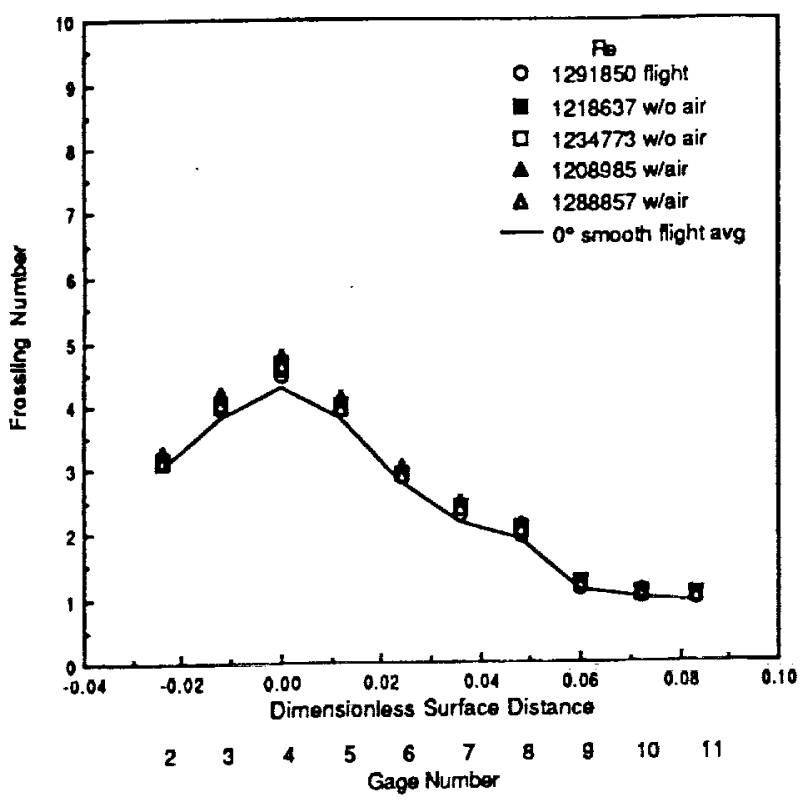

Figure 7. Froseling Number versus dimensionleas rurface distance! smooth airfoll, $0^{\circ}$ angle of attacl, Re -1256, tight and IRT data.

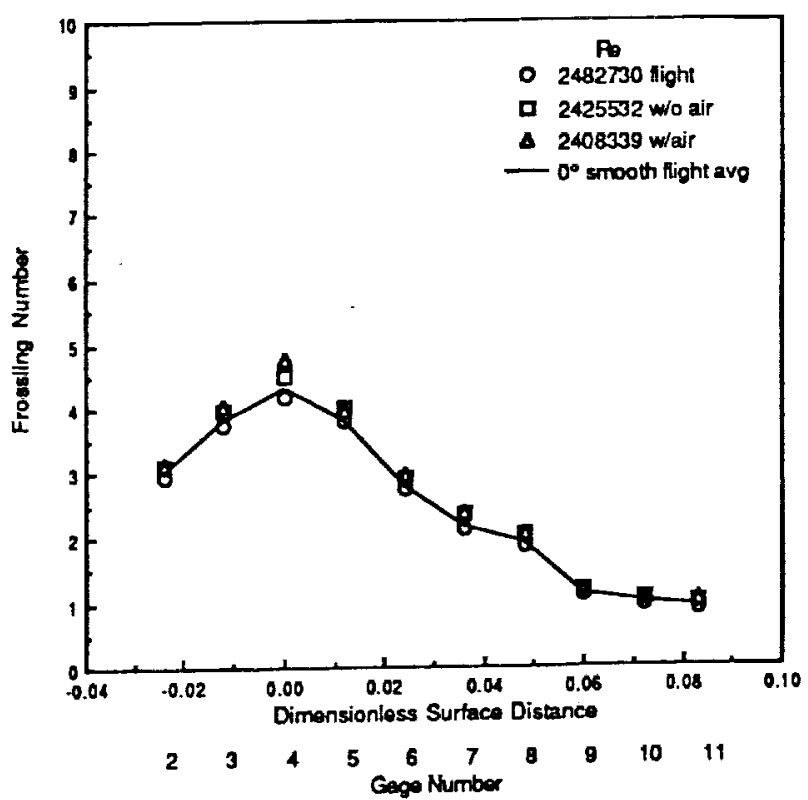

Firore 8. Froeding Number versus dimenstonl en wace distance inooth afifoil, $0^{\circ}$ angle of attact, the 2456 , Aight and IRT data. 


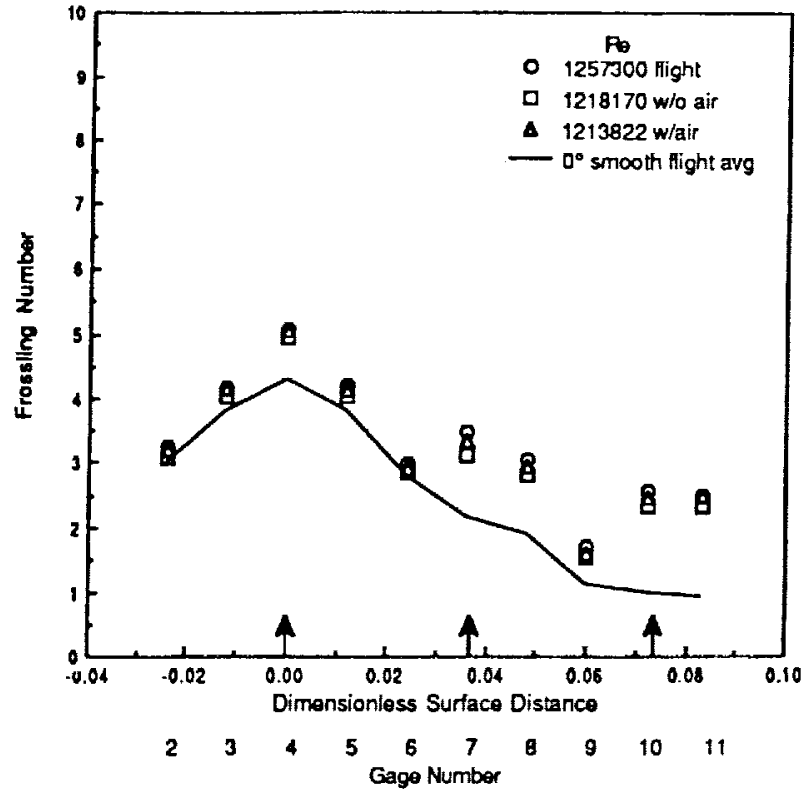

Figure 9. Frossling Number versus dimensionless surface distance sparse roughness, $0^{\circ}$ angle of attack, Re-1.256, fight and IRT data.

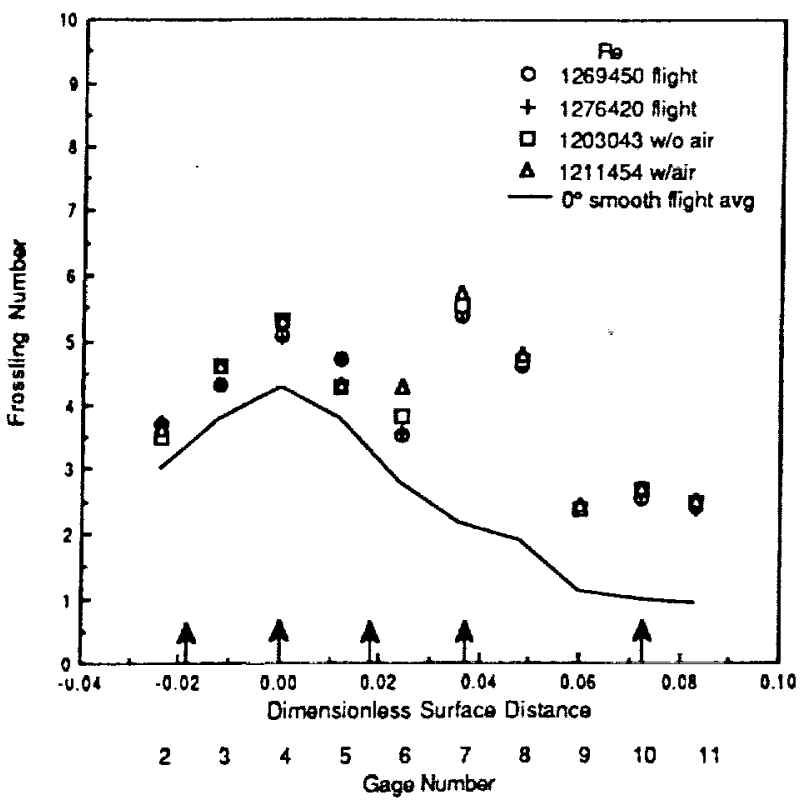

Figure 11. Frowling Number versus dimensionless surface distance: dense 1 roughness, $0^{\circ}$ angle of attack, Re=1.2EG, night and IRT data.

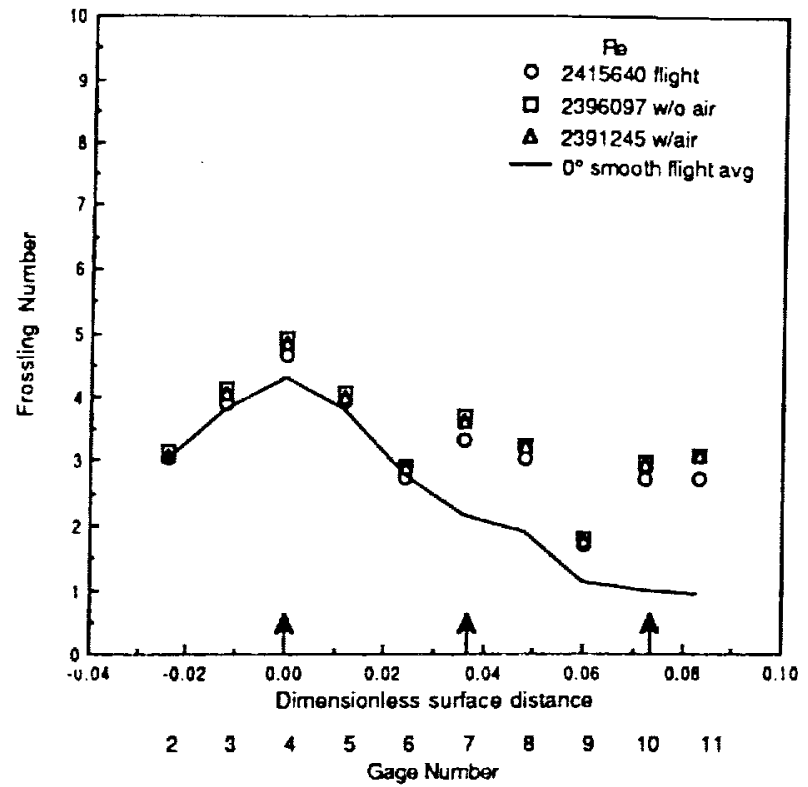

Figure 10. Frossling Number versus dimensionless surface distance: sparse roughness, $0^{\circ}$ angle of attack, Re $-2 A E 6$, flight and IRT data.

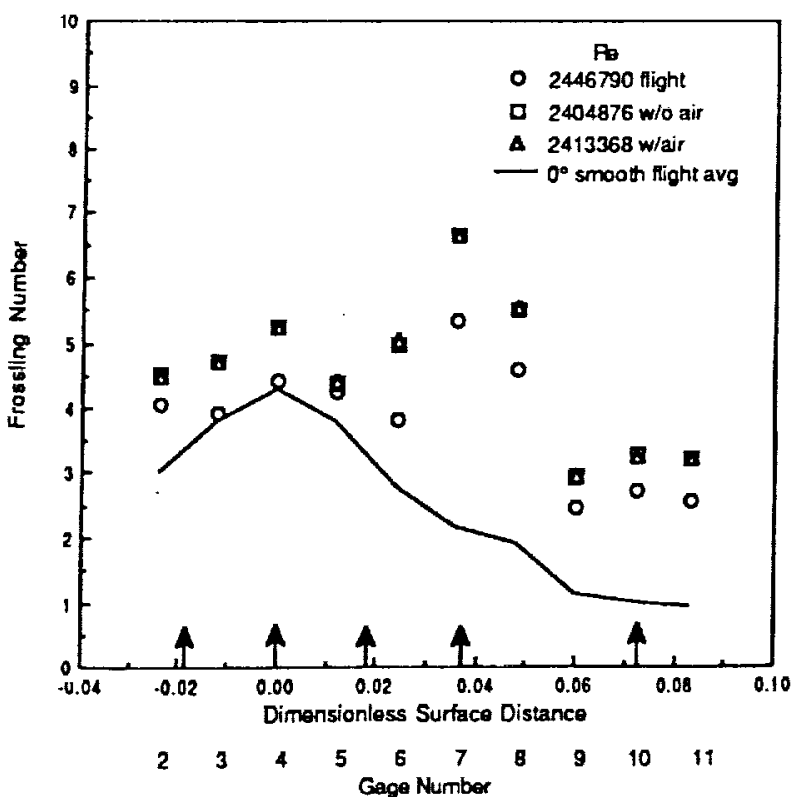

Figure 12. Froelling Number versus dimensionless surface distance: dense 1 roughness, $0^{\circ}$ angle of attack Re -2AE6, Alight and IRT data. 


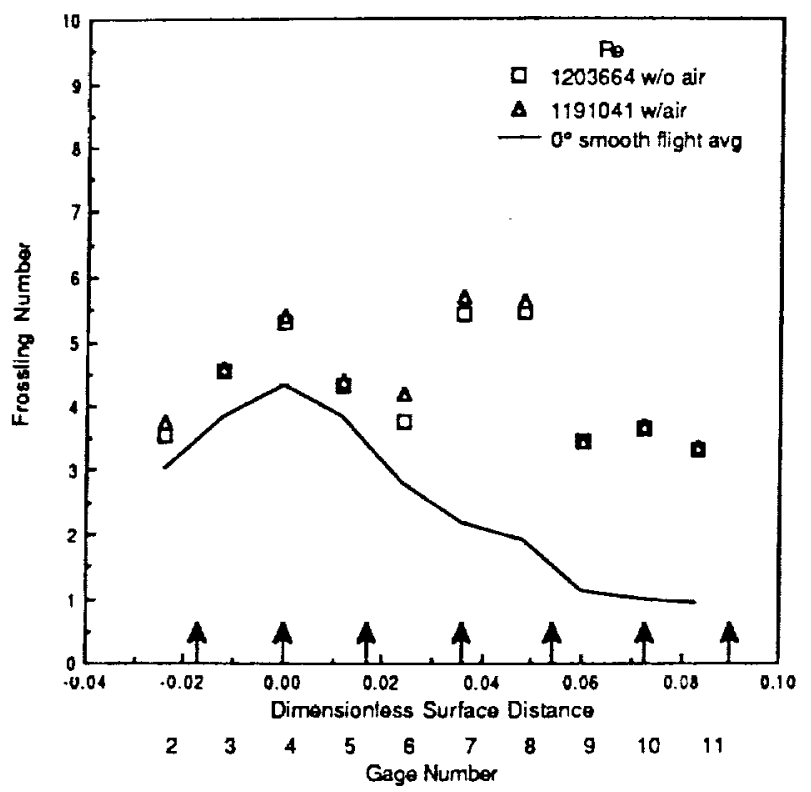

Figure 13. Frossling Number versus dimensionless surface distances dense 2 roughness, $0^{\circ}$ angle of attack, Re $=1.256$, IRT date.

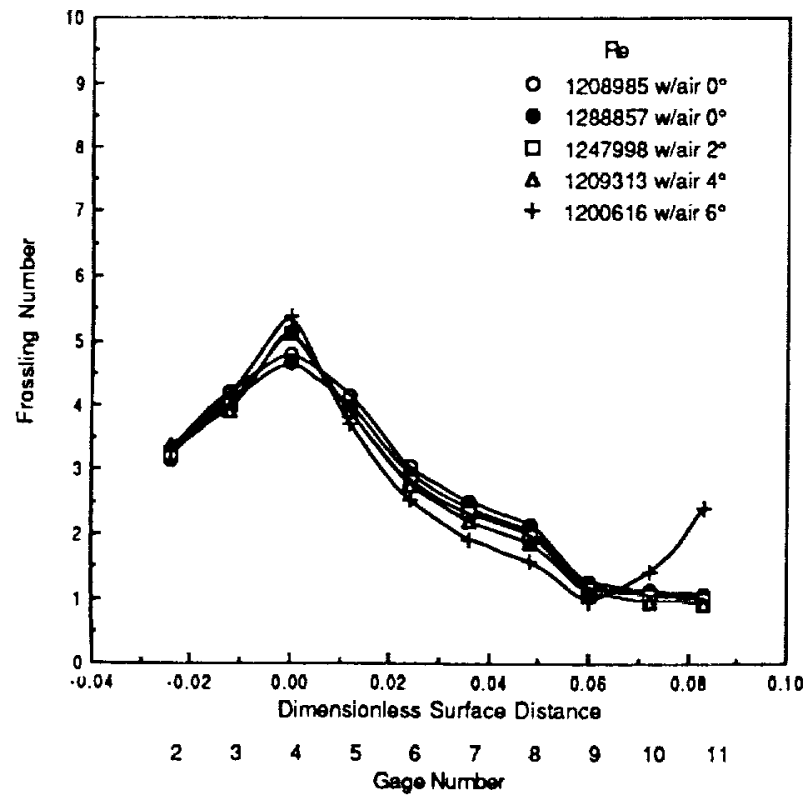

Figure 15. Frossling Number versus dimensionless surface distance smooth airfoll, Re =1.2E6, with spray air, IRT data.

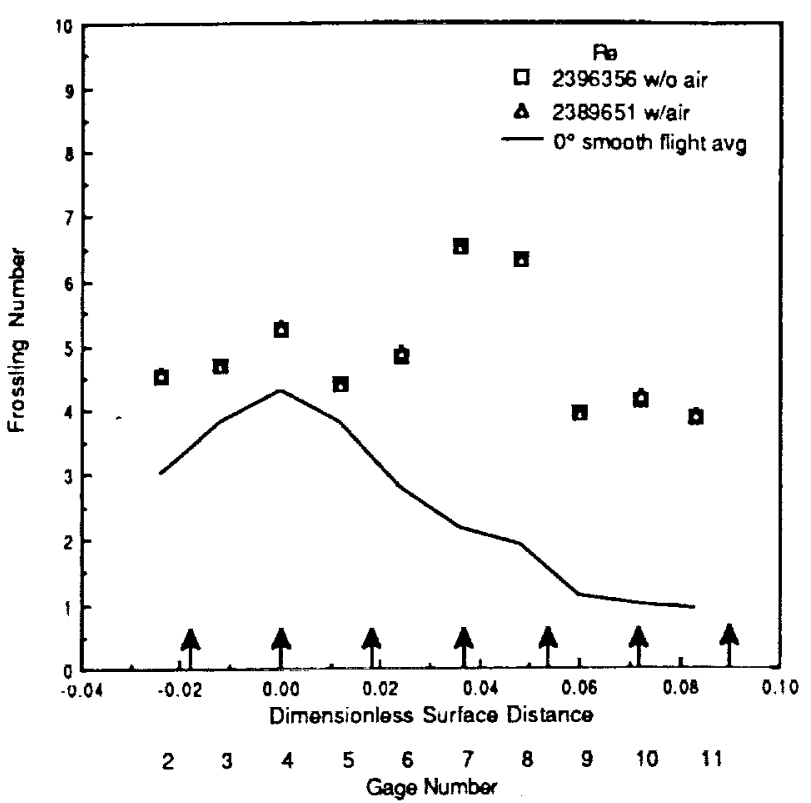

Figure 14. Frossling Number versus dimensionless surface distance dense 2 roughness, $0^{\circ}$ angle of attack, Re $2 A E 6$, IRT data.

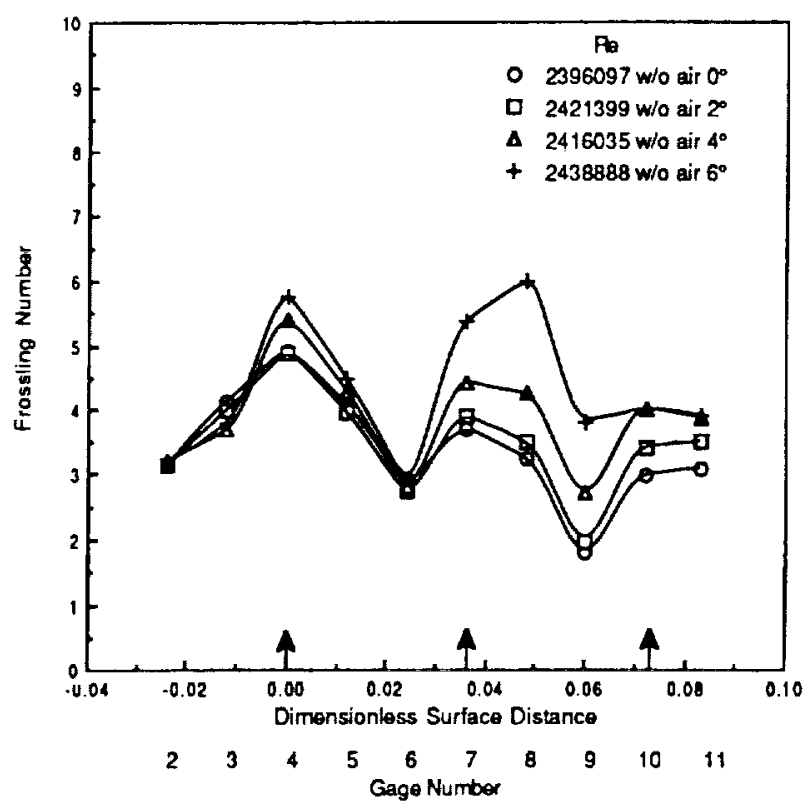

Figure 16. Frossling Number versus dimensionless surface distances sparse roughneas, $R e=24 E 6$, without spray air, IRT date. 


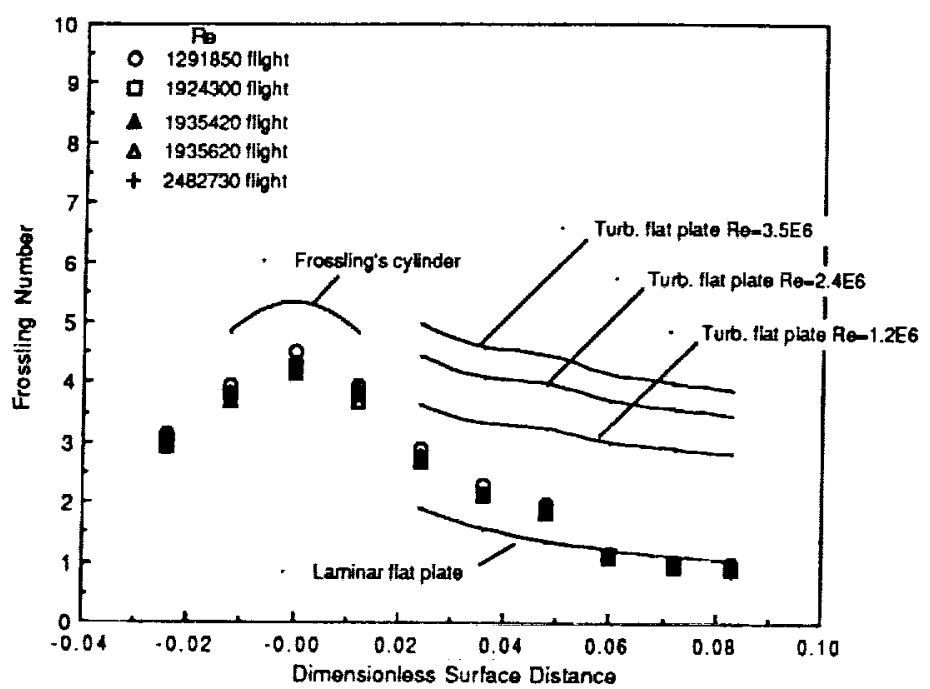

Figure 17. Frossling Number comparison for amooth atrfoil, $\phi^{\circ}$ angle of attack flight data versus Dimensionless Correlations for Cylinder [16] and Flat Plate [17].

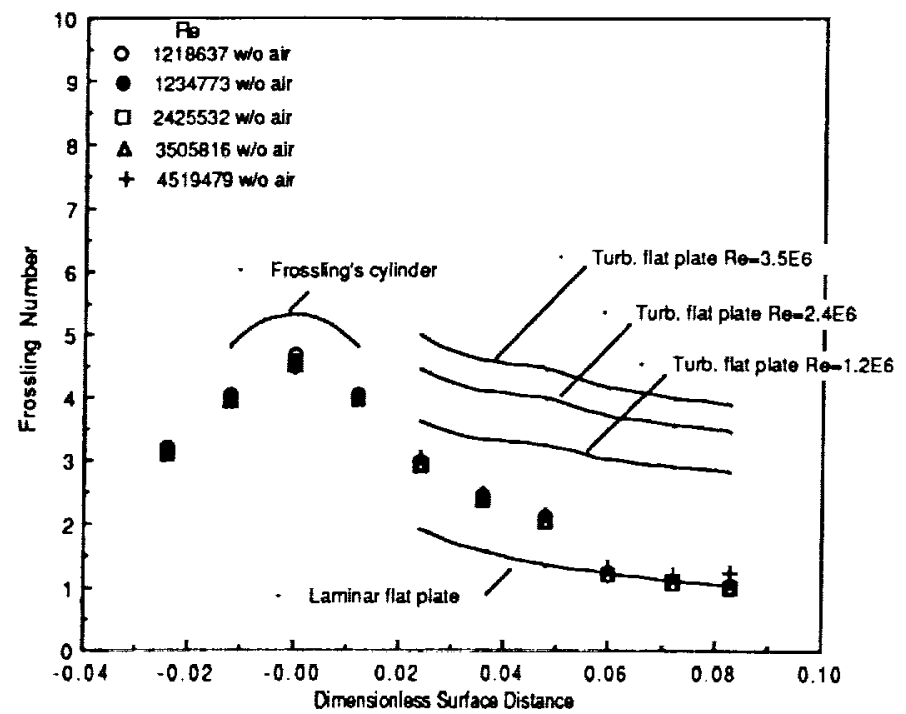

Figure 18. Frossling Number comparison for smooth airfoil, $0^{\circ}$ angle of attack: IRT data (without spray) versus Dimensionless Correlations for Cylinder [16] and Flat Plate [17].

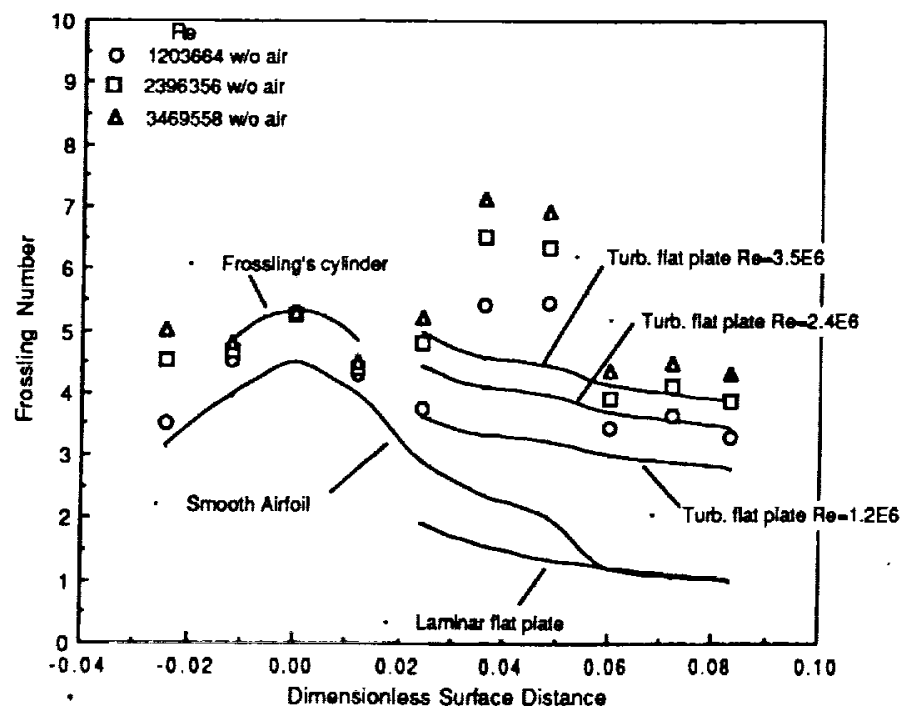

Figure 19. Froesling Number comparison for dense 2 roughnees, $0^{\circ}$ ande of attack: IRT data (without spray) versus Dimensionleos Correlations for Cylinder [16] and Flat Plate [17]. 


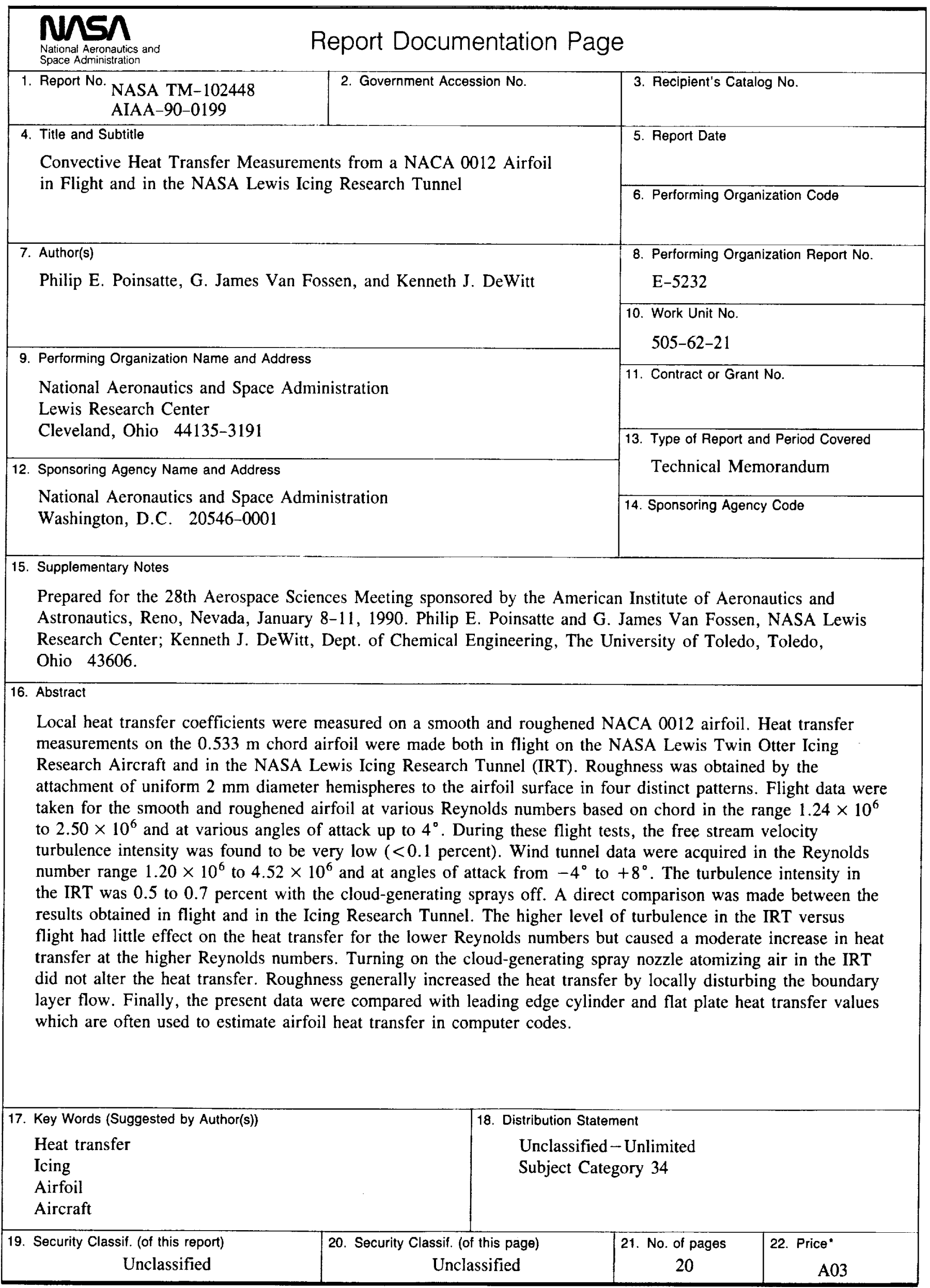


